\title{
Significance of defecography and the role of rectocele in constipated patients
}

\author{
Mehmet Abdussamet Bozkurt, Ahmet Sürek, Murat Gönenç, Mustafa Uygar Kalaycı, Halil Aliş̧
}

Department of General Surgery, Bakırköy Dr. Sadi Konuk Training and Research Hospital, İstanbul, Turkey

Email: msametbozkurt@yahoo.com

Received 14 January 2012; revised 6 March 2012; accepted 12 March 2012

\begin{abstract}
Backround: Chronic constipation is a common, chronic and frequent problem of the general population. The aim of this study is to assess the efficacy of defecography in diagnosing the etiology of constipation and the relation between constipation and rectocele. Material-method: We have investigated 250 patients who have been admitted to our general surgery outpatient clinic with complaint of constipation using Rome III criteria and diagnostic defecography. Results: Out of 250 patients who were evaluated with defecography only 24 had normal findings. 136 patients were found to have rectocele. Conclusion: We propose that rectocele is an important etiology of constipation, and defecography should be considered early in the diagnosis of rectocele.
\end{abstract}

Keywords: Defecography; Rectocele; Chronic Constipation

\section{INTRODUCTION}

Constipation is a major medical problem affecting $2 \%$ to $28 \%$ of the population [1]. Individual patients may have different conceptions of what constipation is, and the findings overlap with those in other functional gastrointestinal disorders. In 1999, an international panel of experts laid out specific criteria for the diagnosis of constipation known as the Rome III criteria. (Table 1) When patients present with complaints of constipation, a complete history and physical examination may help elicit the cause of constipation.

Constipation is functionally separated into the following subgroups: slow colonic transit, normal colonic transit, and defecatory or rectal evacuation abnormalities [2]. Disorders that are associated with pelvic floor dysfunction (puborectalis syndrome, descending perineal syndrome), solitary rectal ulcer syndrome, and rectocele are considered functional anorectal disorders. Symp toms of "constipation" are difficult to associate with a specific patho-
Table 1. Diagnostic criteria of ROME III.

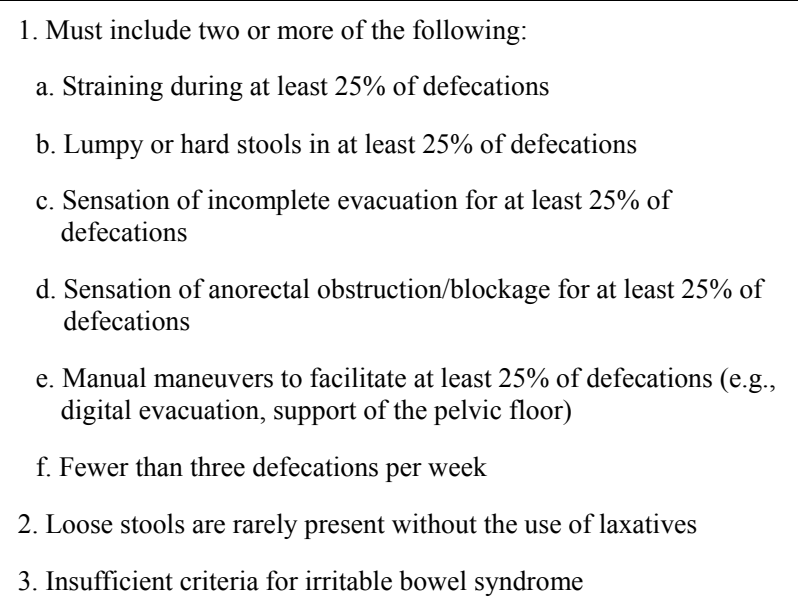

"Criteria fulfilled for the last 3 months with symptom onset at least 6 months prior to diagnosis.

physiologic subgroup. Diagnosing functional anorectal disorders is difficult. A detailed history can be difficult to elucidate, subjective sensations may not be easily described in consistent terms, and symptoms are frequently variable in manifestation and transient in nature. Defecography, anometry, and electromyography (including pudendal nerve terminal motor latency) are frequently used for diagnosis.

The morphologic and dynamic examination of the anorectal region and the pelvic floor is possible by means of defecography. This technique was first described by Wallden in 1953 [3]. During recent decades, interest in the study of evacuation has grown; today it can also be performed with magnetic resonance imaging (MRI). Nonetheless, this technique still represents a widely available and cost-effective diagnostic tool [4-9].

Evacuation disorders, frequently found in elderly patients, are often caused by morphologic and functional abnormalities that are unlikely to be identified with static imaging techniques. Defecography evaluates in real time, the morphology of rectum and anal canal in correlation with pelvic bony components. Injection of a thick barium 
paste into the rectum and its subsequent evacuation during the defacography provides the evaluation both statically and dynamically. The most common indications are constipation, incomplete evacuation or incontinence (often associated with rectal bleeding), mucous discharge, and perineal pain or discomfort [10]. The technique is also useful for follow-up of patients who have undergone surgery of the pelvic region. Defecography is a cost-effective procedure, simple to perform and widely available in every hospital equipped with a fluoroscopy room. This method has the highest accuracy in diagnosing rectal intussusception, prolapse, and enteroceles. The main limitation of this technique is patient exposure to ionizing radiation in comparison with MR defecography, but MR defecography has limited availability. Defecography still represents a unique diagnostic technique for the examination of defecation dysfunctions' etiology like rectocele, intussusception, enterocele, puborectalis spasm [11].

The aim of this study is to assess the efficacy of defecography in diagnosing the etyology of constipation and the relation between constipation and rectocele.

\section{MATERIAL-METHOD}

250 patients who admitted to our general surgery outpatient clinic with a complaint of constipation, (like manual maneuvers, straining during defecation) between January 2009 and January 2011 were included in this study.

All the patients were diagnosed with constipation according to Rome III criteria (Table 1). In the first step colonic transit time were measured. Patients with slow colonic transit time were not included in this study. Patients with normal colonic transit and anorectal outlet obstruction were included the study.

Patients were evaluated by history and physical examination to exclude secondary causes of constipation. Those who had findings (rectal hemoragy vs.) that predict cancer in physical examination were excluded from the study. Findings of hemorrhoid or anal fissure in physical examination were also considered as exclusion criteria because they lead to difficulty in defecation. Patients who had medical conditions that have role in etiology of constipation like psychiatric drug use or diseases like diabetes were not included in this study.

Patients were also assessed by hemogram, BUN, cre, ast, alt, ca, na, k, p, mg, glu and thyroid function tests. Patients who had electrolyte imbalance (hypokalemia, hypophosphatemia, hypocalcemia), hypothyroidism and anemia were excluded because these are secondary causes of constipation.

All of the patients then had a defecography evaluation. Contrast medium (a mixture of barium and wheat flour) was infused into the rectum until the patients had a sen- sation of defecation (approximately $250 \mathrm{ml}$ ). After the infusion patients underwent defecography in physiologic defecation position.

\section{RESULTS}

$48(19.2 \%)$ of patients were male and $202(80.8 \%)$ were female. Mean age was 35 for males, and 37.8 for females. All patients had complaint of constipation.

Defecography in women showed anterior rectocele and internal mucosal intussusception in 114 (56.4\%) (Figure 1), only rectocele in $22(10.8 \%)$ (Figure 2), puborectal spasm in $13(6.4 \%)$, mucosal intussusception in $15(7.4 \%)$, total pelvic dessensus in $7(3.4 \%)$, sigmoidocele in $1(0.49 \%)$, rectal prolapsus in $1(0.49 \%)$, megarectum in $8(3.9 \%)$, doligocolon in $5(2.4 \%)$, hypertonic rectosigmoid junction $1(0.49 \%)$, rectovaginal fistula in 1 $(0.49 \%)$ of the patients. $14(6.9 \%)$ of the female patients had normal defecogarphic findings.

Defecography in men showed internal mucosal intussuseption in $27(56.2 \%)$, puborectalis spasm in $7(14.5 \%)$, doligocolon in $2(4.1 \%)$, megarectum in $2(4.1 \%)$ patients. There were normal defecographic findings in 10

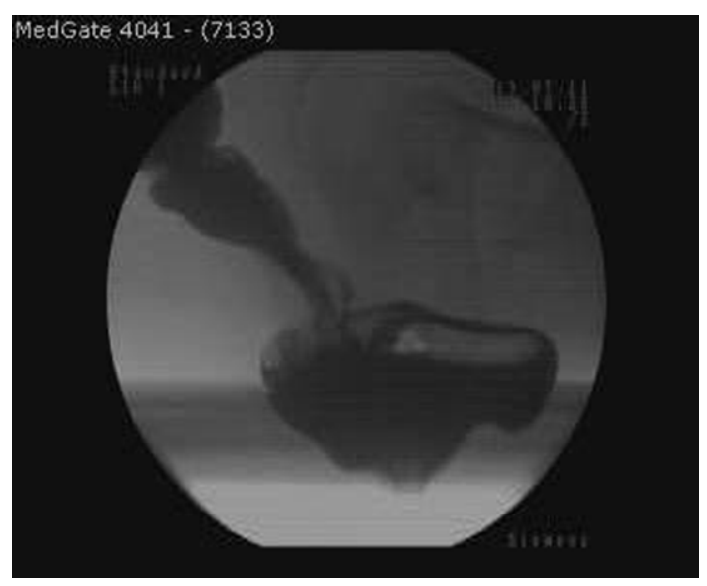

Figure 1. Rectocele and intusseption.

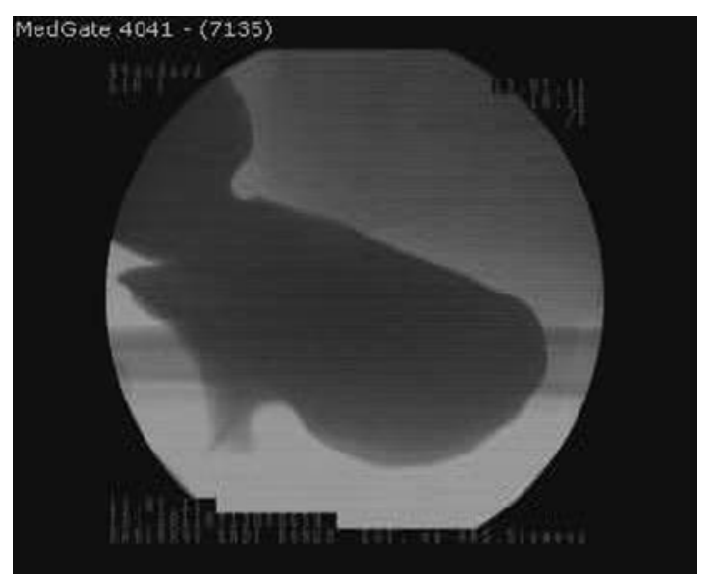

Figure 2. Rectocele. 
(20.8\%) of 48 male patients.

Only 24 of 250 patients who admitted to our clinic with a complaint of constipation and who were eveluated by defecography had normal defecographic findings.

\section{DISCUSSION}

Constipation has plagued human beings since the beginning of time. Constipation is a problem for over 33 million adults in the United States and accounts for 2.5 million physician visits and 92,000 hospitalizations each year [12]. For Turkey we don't know the prevalance of constipation and we could not describe the main etiological problem.

Women are three times more likely than men to suffer from constipation and are more likely to have pelvic floor dysfunction [13]. In our study we found a higher incidence in females than males $(202(80.8 \%)$ female and 48 (19.2\%) male).

Studies showed that incidence of constipation increase by age [14-20]. The reason of this increase is probably the decrease in motility. But in our study mean age of the patients was 36.9 .

There are multiple causes of constipation which can be categorized into those caused by mechanical obstruction, metabolic causes, neurologic diseases, psychiatric diseases, and medications. In our study we tried to exclude such diagnoses that can be assessed within the purvue of our examination. But without a diagnosis of psychiatric or neurological disorders can be skipped because they did not do a detailed psychiatric examination.

Anorectal outlet obstruction is a form of chronic constipation in which pan-colonic transit time is normal but there is delayed transit in the rectosigmoid segment. Some of these patients have dilatation of the rectum and/ or colon (megacolon), while others suffer from a spasm of the pelvic floor muscles, resulting in resistance to defecation (anismus). Patients with megacolon may have loss of the normal myenteric plexus ganglion cells (Hirschsprung disease) or have idiopathic megacolon. Anismus is a condition in which the anal sphincter paradoxically contracts rather than relaxes on attempted defecation. Anismus is also known as spastic pelvic floor syndrome, levatorani syndrome, paradoxical puborectalis contraction, and anorectaldyssynergia. This disorder can be demonstrated on dynamic studies, such as evacuation defecography $[21,22]$. Clinical studies suggest that up to $38 \%$ of patients with constipation have evidence of impaired rectal emptying by evacuation proctography [23, 24]. In our study 24 patients had normal defecography and 226 patients had rectal emptying problem.

Rectocele, which is a protrusion or herniation of the rectal wall, was the most may write frequent problem in our study. The herniation is usually anteriorly, and pa- tients describe either having to push the posterior vaginal wall or rectal digitation to have a bowel movement. Rectocele is more common in women because of obstetric factors such as multiparity and traumatic births. Rectocele is the most common cause of obstructed evacuation treated by surgery. It consists of an anterior bulge of the rectal wall wider than $2 \mathrm{~cm}$ in the anteroposterior diameter [25]. This condition is most commonly found in females because of laxity of the rectovaginal septum (congenital or caused by obstetrical traumas or surgical procedures). Outpouchings smaller than $2 \mathrm{~cm}$ are frequently found in asymptomatic females; these outpouchings are without clinical significance and are not considered pathological. Outpouchings larger than $2 \mathrm{~cm}$ are significantly associated with evacuation disorders. On defecography, an anterior outpouching of the anterior rectal wall bulges and dislocates the opacified vaginal lumen during straining and evacuation. The diagnosis of rectocele is based on both the clinical picture and the results of defecography. In a study of 2816 patients with constipation, $27 \%$ had rectocele (of there $27 \%>4 \mathrm{~cm}$ ) [26]. In a study of 23 nulliparous, healthy women who underwent defecography, $81 \%$ had a rectocele [27] but only one woman had a rectocele greater than $2 \mathrm{~cm}$. Rectocele greater than $2 \mathrm{~cm}$ are associated with in period rectal emptying on defecography [28]. The relevance of rectocele has varied in the literature, with some authors emphasizing size greater than $3 \mathrm{~cm}$ or rectocele with retained contrast material as rectocele that are clinically significant [29,30]. Other authors have used rectocele greater than $4 \mathrm{~cm}$ with delayed or absent emptying as their guidelines for rectocele relevance [31]. Defecography does not predict the outcome of rectocele repair but identifies the anatomy and any other pathologic abnormalities [32].

The relationship between rectocele and constipation is currently uncertain. Arnold and colleagues reported a series in which constipation persisted in the majority of patients following rectocele repair [33]. Sarles and colleagues have stated that three factors should be demonstrated to delineate a cause-and-effect relationship between a rectocele and anorectal outlet obstruction: 1) the necessity for a digital vaginal maneuver to assist defecation; 2) defecography demonstrating the rectocele with evidence of retained stool; 3) defecography permitting the recognition of associated lesions, such as rectal intussusception [34].

\section{CONCLUSIONS}

In this study 250 patients who were admitted to our clinic with a complaint of constipation, were evaluated by defecography; only $24(9.8 \%)$ of them had normal defecographic findings. Ratio of normal defecography 
was higher in men. Rectocele and intussusception were the most common pathologies in both sexes. According to us defecography is a first line diagnostic procedure in patients with constipation.

The incidence of rectocele was $68 \%$ in women with constipation in our study, however the prevalence of rectocele in general population in Turkey has not been determined.

The question is this: Is the rectocele the cause or the consequence of constipation? Further studies are needed to explain this question. But we believe that rectocele is important in the etiology of constipation and defecography are the first line procedure in diagnosis of rectocele and intusseption.

\section{REFERENCES}

[1] Rao, S.S. (2008) Dyssynergic defecationand biofeedback therapy. Gastroenterology Clinics of North America, 37, 569-586. doi:10.1016/j.gtc.2008.06.011

[2] Öztürk, R. and Rao, S.S. (2007) Defecation disorders: An important subgroup of functional constipation, its pathophysiology, evaluation and treatment with biofeedback. The Turkish Journal of Gastroenterology, 18, 139-149.

[3] Wallden, L. (1953) Roentgen examination of the deep rectogenital pouch. Acta Radiologica, 39, 105-116. doi:10.3109/00016925309136693

[4] Brodén, B. and Snellman, B. (1968) Procidentia of the rectum studied with cineradiography: A contribution to the discussion of causative mechanism. Diseases of the Colon \& Rectum, 11, 330-347. doi:10.1007/BF02616986

[5] Mahieu, P.H., Pringot, J. and Bodart, P. (1984) Defecography: 1. Description of a new procedure and results in normal patients. Gastrointestinal radiology, 9, 247-251. doi:10.1007/BF01887845

[6] Mahieu, P.H., Pringot, J. and Bodart, P. (1984) Defecography: 2. Contribution to the diagnosis of defecation disorders. Gastrointestinal radiology, 9, 253-261. doi:10.1007/BF01887846

[7] Ganeshan, A., Anderson, E.M., Upponi, S., et al. (2008) Imaging of obstructeddefecation. Clinical Radiology, 63, 18-26. doi:10.1016/j.crad.2007.05.015

[8] Roos, J.E., Weishaupt, D., Wildermuth, S., et al. (2002) Experience of 4 years with open MR defecography: Pictorial review of anorectal anatomy and diseases. $R a-$ diographics, 22, 817-832.

[9] Mezwa, D.G., Feczko, P.J. and Bosanko, C. (1993) Radiologic evaluation of constipation and anorectal disorders. Radiologic Clinics of North America, 31, 13751393.

[10] Shorvon, P.J., McHugh, S., Diamant, N.E., et al. (1989) Defecography in normal volunteers: Results and implications. Gut, 30, 1737-1749. doi:10.1136/gut.30.12.1737

[11] Matikainen, M. (1994) Does defecography help in diagnosis and clinical decision-making in defecation disorders? Abdom Imaging, 19, 355-358.
[12] Morley, J.E., (2007) Constipation and 1rritable bowel syndrome in the elderly. Clinics in Geriatric Medicine, 23, 823-632. doi:10.1016/j.cger.2007.06.008

[13] Toglia, M.R. (2009) Pathophysiology of anal incontinence, constipation, and defecatory dysfunction. Obstetrics \& Gynecology Clinics of North America, 36, 659671. doi:10.1016/j.ogc.2009.08.004

[14] Pare, P., Ferrazzi, S., Thompson, W.G., et al. (2001) An epidemiological survey of constipationin Canada: Definitions, rates, demographics, and predictors of health care seeking. The American Journal of Gastroenterology, 96, 3130-3137. doi:10.1111/j.1572-0241.2001.05259.x

[15] Thompson, W.G. and Heaton, K.W. (1980) Functional bowel disorders in apparently healthy people. Gastroenterology, 79, 283-288.

[16] Donald, I.P., Smith, R.G., Cruikshank, J.G., et al. (1985) A study of constipation in the elderly livingat home. Gerontology, 31, 112-118. doi:10.1159/000212689

[17] Whitehead, W.E., Drinkwater, D., Cheskin, L.J., et al. (1989) Constipation in the elderly living at home. Definition, prevalence, and relationship to lifestyle and health status. Journal of the American Geriatrics Society, 37, 423-429.

[18] Campbell, A.J., Busby, W.J., Horwath and C.C. (1993) Factors associated with constipation in a community based sample of people aged 70 years and over. Journal of Epidemiology \& Community Health, 47, 23-26. doi:10.1136/jech.47.1.23

[19] Marfil, C., Davies, G.J. and Dettmar, P.W. (2005) Laxative use and its relationship with straining in a London elderly population: Free-living versus institutionalised. The Journal of Nutrition Health and Aging, 9, 185-187.

[20] Wolfsen, C.R., Barker, J.C. and Mitteness, L.S. (1993) Constipation in the daily lives of frail elderly people. Archives of Family Medicine, 2, 853-858. doi:10.1001/archfami.2.8.853

[21] Kuijpers, H.C. and Bleijenberg, G. (1985) The spastic pelvic floor syndrome: A cause of constipation. Diseases of the Colon \& Rectum, 28, 669-672. doi:10.1007/BF02553449

[22] Read, N.W., Timms, J.M., Barfield, L.J., et al. (1986) Impairment of defecation in young women with severe constipation. Gastroenterology, 90, 53-60.

[23] Wald, A., Caruana, B.J., Freimanis, M.G., et al. (1990) Contributions of evacuation proctography and anorectal manometry to evaluation of adults with constipation and defecatory difficulty. Digestive Diseases and Sciences, 35, 481-487. doi:10.1007/BF01536923

[24] Jones, P.N., Lubowski, D.Z., Swash, M., et al. (1987) Is paradoxical contraction of puborectalis muscle of functional importance? Diseases of the Colon \& Rectum, 30, 667-70. doi:10.1007/BF02561685

[25] Arnold, M.W., Steart, W.R. and Aguilar, P.S. (1990) Rectocelerepair: Fouryears' experience. Diseases of the Colon \& Rectum, 33, 684-687. doi:10.1007/BF02150745

[26] Lembo, A. and Camilleri, M. (2003) Chronic constipation. The New England Journal of Medicine, 349, 1360-1368. 


\section{doi:10.1056/NEJMra020995}

[27] Shorvon, P.J., McHugh, S., Diamant, N. E., Somers, S. and Stevenson, G. W. (1989) Defecography in normal volunteers: Results and implications. Gut, 30, 1737-1749. doi:10.1136/gut.30.12.1737

[28] Karlbom, U., Nilsson, S., Pahlman, L. and Graf, W. (1999) Defecography study of rectal evacuation in constipated patients and control subjects. Radiology, 210, 103-108.

[29] Siproudhis, L., Ropert, A., Lucas, J., et al. (1992) Defecatory disorders, anorectal and pelvic floor dysfunction: A polygamy? International Journal of Colorectal Disease, 7, 102-107. doi:10.1007/BF00341295

[30] Turnbull, G.B., Bartram, C.I. and Lennard-Jones, J.E. (1988) Radiologic studies of rectal evacuation in adults with idiopathic constipation. Diseases of the Colon \& Rectum, 31, 190-197. doi:10.1007/BF02552545

[31] Bartolo, D.C., et al. (1988) Symposium: Proctography. International Journal of Colorectal Disease, 3, 67-89.

[32] Dam, J.H., Ginai, A.Z., Gosselink, M.J., et al. (1997) Role of defecography in predicting clinical outcome of rectocele repair. Diseases of the Colon \& Rectum, 40, 201-207. doi:10.1007/BF02054989

[33] Arnold, M.W., Stewart, W.R.C. and Aguilar, P.S. (1990) Rectocelerepair: Fouryears' experience. Diseases of the Colon \& Rectum, 33, 684-687. doi:10.1007/BF02150745

[34] Sarles, J.C., Arnaud, A., Selezneff, I., et al. (1989) Endorectal repair of rectocele. International Journal of Colorectal Disease, 4, 167-171. doi:10.1007/BF01649696 